\title{
¿POR QUÉ LOS ARRENDADORES PREFIEREN LA ACCIÓN DE PRECARIO?
}

\section{WHY LESSORS PREFER THE PRECARIOUS ACTION?}

\author{
VALERIA ORTIZ VÉLIZ* \\ Licenciada en Cs. Jurídicas \\ Universidad Católica del Norte \\ Coquimbo - Chile
}

\section{RESUMEN}

El dueño de un inmueble arrendado prefiere demandar al arrendatario usando el precario en lugar de alguna de las acciones que nacen del contrato de arrendamiento. Este ensayo revisa esta práctica, tan arraigada en la litigación en Chile, con un doble propósito: por un lado, identificar las razones que podrían llevar a que el arrendador se comporte como dueño y no como acreedor frente al arrendatario y, por el otro, resaltar algunas de las diferencias prácticas entre el precario y los juicios de arrendamiento, en cuanto al procedimiento aplicable y a la prueba que se necesita para demostrar el contrato. Estos antecedentes demuestran que es necesario repensar seriamente la inclinación de los dueños por el juicio de precario como la forma de conseguir la restitución del inmueble arrendado.

Palabras clave: Precario; arrendamiento; restitución; procedimientos civiles.

* Licenciada en Ciencias Jurídicas de la Universidad Católica del Norte, Coquimbo. Correo electrónico: vov002@alumnos.ucn.cl. Este artículo se basa en mi trabajo de Licenciatura realizado bajo la guía del profesor Jorge Larroucau Torres. Artículo recibido el 7 de junio de 2017 y aceptado para su publicación el 15 de noviembre de 2017. 


\section{ABSTRACT}

Whoever tries to recover their property prefers to sue the lessee using the precarious action instead of any of the actions arising from the lease. This practice, so ingrained in Chile's litigation, needs to be reviewed following two objectives: first, to identify some reasons that could move the lessor to act as owner and not as a creditor against the lease; and, on the other hand, to highlight some of the practical differences, in terms of procedure and evidence necessary to support the lease. This points show that we should seriously rethink this penchant of the owners to use the precarious as a way to get the restitution of their property.

Keywords: Precarious; lease; restitution; civil proceedings.

\section{INTRODUCCIÓN}

La acción de precario (art. 2195 inc. $2^{\circ}$ del Código Civil) no sólo ha desplazado a la acción reivindicatoria -y a otras acciones reales- en la práctica judicial chilena que versa sobre la propiedad y la posesión de inmuebles, sino que también ha ocupado el lugar de ciertas acciones personales. Así ha ocurrido, por ejemplo, con las acciones que nacen del contrato de arrendamiento.

Como es bien sabido, la jurisprudencia ha dicho constantemente que el precario es una "situación de hecho" que describe el caso en que alguien ocupa una cosa sin tener un antecedente que lo avale y por ignorancia o mera tolerancia del dueño. ${ }^{1}$ Esta "situación de hecho" no tendría lugar en los casos en que sí hay un vínculo contractual que puede justificar la tenencia del bien, como acontece con el arriendo de un inmueble. Por lo tanto, si se pretende recuperar un inmueble que está en manos de un arrendatario porque él, por ejemplo, ha dejado de pagar la renta, no sería sensato acudir al precario ya que el demandado se defendería exitosamente probando el arriendo. Lo que el dueño tendría que hacer en estos casos es acudir a las acciones y a los procedimientos que surgen del propio arrendamiento.

Pero esto no es lo que ocurre en Chile. En la práctica judicial, los arrendadores muestran una clara preferencia por la acción de precario en 
contra del arrendatario, o del subarrendatario, a la hora de buscar la restitución del inmueble, aun a pesar del evidente riesgo que supone para su pretensión el que el juez considere al arriendo como un título oponible en su contra. Esta elección no puede explicarse por la rapidez del juicio de precario, ya que en el caso del arrendamiento se dispone de procedimientos que son igual de rápidos, o incluso más expeditos (Título VI, Libro III del Código de Procedimiento Civil, arts. 588 a 616; Ley $\mathrm{N}^{\circ} 18.101$, predios urbanos; Decreto Ley $\mathrm{N}^{\circ}$ 993, predios rústicos; DL No 1939, inmuebles fiscales).

Este ensayo se propone identificar las razones que moverían a prescindir de las acciones (personales) del arrendamiento y a optar por la acción (real) de precario cuando se trata de recuperar un inmueble arrendado. Para ello se han revisado múltiples sentencias dictadas durante la segunda década de este siglo, tanto de primera instancia como de las Cortes. La conclusión a la que se llega es que no hay una explicación convincente para esta inclinación por el precario. Por el contrario, se trata de una estrategia de litigación que suele dejar en muy mal pie al dueño del inmueble.

Para comprender mejor este problema el análisis se dividirá en dos partes. En primer lugar, se hará referencia a las razones que podría tener el arrendador para comportarse como dueño y no como acreedor frente al arrendatario. En segundo término, se analizarán las diferencias procedimentales entre el precario y los juicios de arrendamiento, así como la prueba que necesita el demandado para demostrar que existe un contrato. En ambos casos se destacará lo que han resuelto los tribunales al respecto.

\section{II. ¿POR QUÉ EL PRECARIO?}

La práctica a la que se acaba de aludir puede ser ejemplificada, entre muchos otros casos, mediante uno en que la actora dijo haber arrendado, en 2012, un inmueble a la Municipalidad de Estación Central en Santiago, la que a su vez cedió el uso del mismo al Club Deportivo Cultural Las Atahualpa para fines asociativos, el cual lo subarrendó a la parte demandada a pesar que la cláusula sexta del contrato prohibía expresamente tal subarriendo, a menos que se tuviese la autorización previa y por escrito de la dueña, lo que no se probó en el juicio.

La dueña del inmueble demandó a la subarrendataria la restitución del bien por medio del precario, pero el Vigésimo Juzgado Civil de Santiago rechazó la acción porque el precario no es la vía adecuada para resolver este conflicto, toda vez que el precario solo procede cuando se ocupa una cosa sin un título que lo justifique y el arriendo -cuya copia fue acompañada por la 
misma actora, ya que la demandada estaba en rebeldía- basta para justificar esta tenencia. $^{2}$

Esto es lo que la jurisprudencia ha resuelto de manera sistemática durante décadas: cada vez que se pruebe la existencia de un arrendamiento los tribunales no pueden acoger una demanda de precario. ${ }^{3}$

El camino que la actora debió seguir en un caso como el recién citado era interponer una acción personal derivada del propio arrendamiento, usando para ello un procedimiento especial (la Ley $\mathrm{N}^{\circ} 18.101$ enseña la manera en que se le pone fin a un subarriendo) y amparada en una causa de pedir específica: solicitar el término del arrendamiento y la restitución del bien por haberse incumplido una de las cláusulas contractuales, la de no subarrendarlo sin su autorización.

En este sentido, en Contreras con Santibáñez el Vigésimo Juzgado Civil de Santiago consideró que la opción por el precario era tan injustificada que la demandante debía pagar las costas del juicio, condena que no es excepcional en situaciones como ésta.

Siendo así las cosas, ¿por qué los dueños de inmuebles arrendados creen disponer de dos caminos distintos para recuperarlos, los juicios de arrendamiento y el juicio de precario? Pueden sugerirse, al menos, tres respuestas a esta pregunta, todas ellas compatibles entre sí. Las dos primeras hipótesis solo serán mencionadas, pero a la tercera habrá que referirse con cierto detalle destacando lo resuelto por la jurisprudencia reciente:

\section{La prueba del incumplimiento contractual}

El dueño del inmueble prefiere el precario porque la prueba del incumplimiento del contrato es una cuestión difícil; o, al menos, más difícil que la prueba del dominio en el precario, que es "sumaria" y no "diabólica" como en la acción reivindicatoria. ${ }^{4}$ Para ponderar si esta hipótesis es una buena respuesta a la pregunta en cuestión habría que investigar cómo funciona la prueba del incumplimiento en los juicios de arrendamiento, pero desde ya se podría descartar esta explicación considerando la posibilidad de recuperar el

2 Contreras con Santibánez: Vigésimo Juzgado Civil de Santiago, 19 de agosto de 2013, Rol No 5332-2013, cons. $6^{\circ}$ y $8^{\circ}$ (redacción de la Jueza Gabriela Silva).

3 Rostión CASAS, Ignacio, El precario en la jurisprudencia chilena (1996 a 2013), LegalPublishing, Santiago, 2014, pp. 55-66.

4 Larroucau Torres, Jorge, "La 'prueba completa' del dominio en la acción reivindicatoria", en: Turner, Susan; Varas, Juan A. (coords.), Estudios de Derecho Civil IX, Thomson Reuters, Santiago, 2014, pp. 109-112. 
bien ocupado por el demandado sin necesidad de probar un incumplimiento del contrato mediante el desahucio (art. 1951 del Código Civil). ${ }^{5}$

\section{El segundo intento judicial}

El arrendador se inclina por el precario simplemente porque ya intentó recuperar el bien mediante un juicio de arrendamiento, pero perdió el juicio. Esta posibilidad exige hacerse cargo de los límites de la cosa juzgada a la luz de la triple identidad del art. 177 CPC (que el Proyecto de Código Procesal Civil de 2012 propone reemplazar por la categoría de "lo deducido y lo deducible", Boletín No 8197-07), además de las ventajas y desventajas de la figura de la acumulación inicial de acciones en relación con una teoría del caso.

\section{La apuesta por el título}

El propietario demanda de precario porque confía en que el título del demandado no será considerado un antecedente oponible en su contra. Esto acontece especialmente cuando el arrendamiento fue celebrado con una persona distinta de quien entabla la demanda. En este sentido, el debate radica en saber si estos arriendos son o no oponibles al actual dueño, cuestión que nos lleva a la interpretación de dos reglas del contrato de arrendamiento: los arts. $1950 \mathrm{~N}^{\circ} 3^{6}$ y $1962 \mathrm{~N}^{\circ} 2$ del Código Civil. ${ }^{7}$

Primero que todo hay que recordar que, en general, los jueces reconocen como antecedente oponible a quien demanda de precario algunos títulos que no han emanado del dueño, ${ }^{8}$ porque lo crucial no es su origen, sino justamente que le sea oponible al propietario. ${ }^{9}$

\footnotetext{
${ }^{5}$ Art. 1951 inciso $1^{\circ} \mathrm{CC}$ : "Si no se ha fijado tiempo para la duración del arriendo, o si el tiempo no es determinado por el servicio especial a que se destina la cosa arrendada o por la costumbre, ninguna de las dos partes podrá hacerlo cesar sino desahuciando a la otra, esto es, noticiándoselo anticipadamente".

6 Art. 1950 CC: "El arrendamiento de cosas expira de los mismos modos que los otros contratos, y especialmente: $3^{\circ}$. Por la extinción del derecho del arrendador, según las reglas que más adelante se expresarán".

7 Art. 1962 CC: "Estarán obligados a respetar el arriendo: $1^{\circ}$. Todo aquel a quien se transfiere el derecho del arrendador por un título lucrativo; $2^{\circ}$. Todo aquel a quien se transfiere el derecho del arrendador, a título oneroso, si el arrendamiento ha sido contraído por escritura pública; exceptuados los acreedores hipotecarios; $3^{\circ}$. Los acreedores hipotecarios, si el arrendamiento ha sido otorgado por escritura pública inscrita en el Registro del Conservador antes de la inscripción hipotecaria. (2) El arrendatario de bienes raíces podrá requerir por sí solo la inscripción de dicha escritura".

${ }^{8}$ Larroucau y Rostión, cit. (n. 1), pp. 78-79.

9 Ramos Pazos, René, "Del precario", Revista de Derecho Universidad de Concepción, 1986, № 186, p. 13.
} 
En el caso puntual del arriendo pactado con el antiguo dueño, la jurisprudencia ha conservado esta idea. A este respecto es decidora la sentencia del Vigésimo Segundo Juzgado Civil de Santiago, en Salvo con Galdames:

"Al indicar la ley en su segunda hipótesis [art. $1962 \mathrm{~N}^{\circ}$ 2] que si el arrendamiento no ha sido contraído por escritura pública, el adquirente a título oneroso -como el actor- no está obligado a respetarlo, ello no quiere decir que el arrendamiento deje de estar vigente, por el contrario, el vínculo de la demandada con el inmueble sigue vigente y mientras no se le ponga término tienen un título legítimo por el cual detentar la cosa, lo que hace inviable que prospere la acción de precario al incumplirse uno de los requisitos, este es, que la ocupación sea sin previo contrato y por ignorancia o mera tolerancia del dueño". ${ }^{10}$

Esta interpretación extensiva del № 2 del art. 1962 ha hecho que el arriendo celebrado con el antiguo dueño configure un título oponible al dueño que demanda de precario. Lo que resta por saber es si ello ocurre solo cuando el demandante conocía el arriendo o en todos los casos, incluso cuando no sabía del arriendo. Claramente, si el demandante sabía que se había pactado un arriendo no puede alegar ignorancia ni mera tolerancia en la ocupación del inmueble porque, aunque los dueños siempre pongan el énfasis en que ignoraban la tenencia del bien, la jurisprudencia considera que lo relevante no es la ignorancia o el conocimiento de quien demanda de precario, sino la presencia o ausencia de un título que justifique esta tenencia. De allí que, al probar el arriendo, se elimina la posibilidad de tal ignorancia o de la mera tolerancia del dueño, porque el arriendo implica la entrega del bien. ${ }^{11}$

Tampoco proceden las acciones de precario que interponen los herederos del antiguo dueño que negoció con el ocupante, porque ellos son los continuadores de la persona del causante. Por ello que si el anterior dueño

\footnotetext{
${ }^{10}$ Salvo con Galdames: Vigésimo Segundo Juzgado Civil de Santiago, 6 de febrero de 2015, Rol № 18948-2014, cons. $8^{\circ}$ (redacción del Juez Pedro García); Sociedad Ferrando Rojas Limitada con Ceballos y otros: Corte de Apelaciones de Arica, 4 de julio de 2007, Rol No $184-2007$, cons. $5^{\circ}$ y $6^{\circ}$ (redacción de la Ministra Cristina Araya): “Aunque no sea un contrato de arriendo que sea oponible al comprador del inmueble, en virtud de lo dispuesto por el artículo 1962 del Código Civil, constituye un título que justifica la tenencia del mismo".

${ }^{11}$ Coz con Cruzat: Segundo Juzgado de Letras de Talagante, 26 de agosto de 2014, Rol № 264-2013, cons. $2^{\circ}$ (redacción del juez Gerardo Mena).
} 
vendió una parte del bien a los actuales ocupantes, ${ }^{12} \mathrm{o}$ si se los arrendó, ${ }^{13}$ sus herederos no pueden acudir al precario. Incluso se ha llegado a rechazar la acción de precario en un caso en que la persona demandada era la nieta de la arrendataria, ${ }^{14}$ aunque en casos así es más habitual que se acoja el precario: por ejemplo, si el demandado es el hermano del arrendatario (aunque alegue ocupar el inmueble como su mandatario), ${ }^{15}$ o se trata de alguien que estaba casada en sociedad conyugal con el arrendatario..$^{16}$ Con todo, también hay que decir que se ha rechazado la acción de precario interpuesta en contra de la esposa de un carabinero que recibió el bien como vivienda familiar de parte de Carabineros de Chile, a pesar que el funcionario ya había sido dado de baja y no vivía con la esposa al momento en que se la demandó. ${ }^{17}$

¿Y qué ocurre con los arriendos de cosa ajena? Según el artículo 1916 inciso segundo del Código Civil, tal arriendo es válido de modo que se le podría considerar oponible al dueño. ${ }^{18}$ Esta fue la jurisprudencia de la Corte Suprema durante los años noventa, ${ }^{19}$ pero en esta década la Corte Suprema ha cambiado expresamente su criterio, ${ }^{20}$ estimando que este título no es oponible al dueño. Por ejemplo, un arriendo celebrado por el hermano de la dueña no es oponible a ésta. ${ }^{21}$

Conviene observar que se admite el precario en estos casos, no porque se piense que es inoponible un antecedente pactado con un tercero, sino porque

${ }_{12}$ Monroy con Andana y Martínez: Primer Juzgado de Letras de San Carlos, 27 de febrero de 2015, Rol N ${ }^{\circ} 372-2014$, cons. $10^{\circ}$ (redacción de la Jueza Débora Riquelme).

${ }^{13}$ Veas con Vergara y Vergara: Primer Juzgado de Letras de San Felipe, 27 de enero de 2015, Rol N ${ }^{\circ}$ 4039-2014, cons. $8^{\circ}$ (redacción del Juez Jaime Díaz).

${ }^{14}$ Silva con Marchant: Segundo Juzgado de Letras de San Bernardo, 30 de abril de 2013, Rol N ${ }^{\circ}$ 1535-2013, cons. $9^{\circ}$ (redacción de la Jueza Jacqueline Dunlop).

${ }^{15}$ Inmobiliaria e Inversiones Socorro Limitada con Valdebenito: Cuarto Juzgado de Letras de Talca, 28 de agosto de 2014, Rol N 517-2014, cons. $7^{\circ}$ (redacción del Juez Matías de la Noi).

${ }^{16}$ Inmobiliaria Andrea Jara Hermosilla con Jaccard: Segundo Juzgado de Letras de Concepción, 21 de noviembre de 2014, Rol N 7018-2014, cons. $6^{\circ}$ (redacción de la Jueza Ana María Suárez).

${ }^{17}$ Fisco de Chile con Castro: Tercer Juzgado Civil de San Miguel, 19 de diciembre de 2013, Rol No 14077-2011, cons. $16^{\circ}$ (redacción de la Jueza Susana Chacón).

${ }^{18}$ Art. 1916 inciso $2^{\circ} \mathrm{CC}$ : "Puede arrendarse aun la cosa ajena, y el arrendatario de buena fe tendrá acción de saneamiento contra el arrendador, en caso de evicción".

${ }^{19}$ Lagazio con Divasto: Corte Suprema, 22 de mayo de 1995, Rol No 6749, cons. $4^{\circ}$.

${ }^{20}$ Tenis con Más Asesorías Deportivas Ltda. con Inmobiliaria e Inversiones Curacaví S.A.: Corte Suprema, 9 de julio de 2013, Rol N 8304-2012, cons. $17^{\circ}$ (redacción del abogado integrante Víctor Vial).

${ }^{21}$ Toloza con Carrasco: Juzgado de Letras de Buin, 13 de abril de 2015, Rol No 1613-2013, cons. $12^{\circ}$ (redacción de la Jueza María Paz Rodríguez). 
ese tercero no tenía derecho sobre el bien cuando celebró el arriendo. ${ }^{22}$

También son ejemplos de esta amplia jurisprudencia que niega la procedencia del precario en situaciones en que hay un arriendo, los siguientes: si el bien es parte de la comunidad que surgió luego del divorcio de cónyuges que estaban casados en sociedad conyugal, habiendo arrendado el inmueble solo uno de los ex cónyuges, ${ }^{23}$ y el caso de un hijo que arrendó con opción de compra un inmueble de su padre, aunque negociase en nombre del dueño. ${ }^{24}$

En este sentido, es interesante notar que la prueba del arriendo suele volverse más confusa si el actor es un familiar cercano del demandado, como su cónyuge o su hermano por ejemplo. ${ }^{25}$

Finalmente, con respecto al $\mathrm{N}^{\mathrm{o}} 3$ del art. 1962 llama la atención que la jurisprudencia sí se ciñe al tenor de la regla y acepta que un acreedor hipotecario (por ejemplo, un banco que se adjudicó el inmueble en una subasta) demande de precario si el arriendo no fue inscrito en el libro de hipotecas y gravámenes del Registro Conservatorio de Bienes Raíces. ${ }^{26}$

\section{PROCEDIMIENTOS Y PRUEBAS}

Como se sugería en la primera parte de este ensayo, la inclinación por el precario puede responder a diversas razones: a la reticencia del dueño a discutir el incumplimiento del contrato, a la necesidad de evitar la excepción de cosa juzgada, o bien, a la simple osadía del dueño que piensa que en su caso el arriendo no será considerado un antecedente oponible por parte del tribunal.

Sea como fuere, lo cierto es que entre un precario y un juicio de

22 Sarras con López: Vigésimo Sexto Juzgado Civil de Santiago, 20 de agosto de 2014, Rol No 48492014, cons. $7^{\circ}$ (redacción del Juez Humberto Provoste).

${ }^{23}$ Monsalve con Roa: Segundo Juzgado Civil de Talcahuano, 4 de febrero de 2015, Rol No 32672014, cons. $10^{\circ}$ (redacción de la Jueza María Sotomayor): "[si] la demandada ha suscrito el contrato de arrendamiento que sirve de título para justificar su ocupación, con uno de los comuneros, lo que es posible en virtud del mandato tácito y recíproco existente entre ellos, ya que cualquiera puede ejercer actos de administración respecto de dicha comunidad, por lo que este contrato es perfectamente válido. Además, la existencia de conflictos entre los respectivos comuneros, le son inoponibles a quien tiene título válido para ocupar dicha propiedad".

${ }^{24}$ Castillo con Oliva: Décimo Octavo Juzgado Civil de Santiago, 20 de marzo de 2013, Rol N²09572012, cons. $10^{\circ}$ (redacción de la Jueza Claudia Donoso).

${ }^{25}$ Etcheberry Court, Leonor, "El título de precario: Análisis jurisprudencial cuando lo que se invoca como título es una relación de familia. ¿Se desprotege la propiedad?”, en: Corral, H.; Manterola, P. (editores), Estudios de Derecho Civil XII, Thomson Reuters, Santiago, 2016, pp. 73 ss.

${ }^{26}$ BBVA Chile con Velásquez: Segundo Juzgado de Letras de Quilpué, 4 de noviembre de 2014, Rol $\mathrm{N}^{\circ} 1152-2014$, cons. $9^{\circ}$ y $10^{\circ}$ (redacción de la Jueza Paz Cataldo). 
arrendamiento hay diferencias que son considerables desde un punto de vista práctico.

Aquí se hará un examen de dos de estas diferencias: la que dice relación con el procedimiento aplicable y lo relativo a la prueba que se necesita para demostrar el arriendo del bien.

\section{Los procedimientos judiciales}

La jurisprudencia de esta década parece negar de un modo frontal que el dueño tenga un derecho a optar por el precario en lugar de los juicios de arrendamiento. Tomando como ejemplo el típico caso en que se arrendó el inmueble al anterior dueño sin que hubiese escritura pública y el argumento del actor en cuanto a que dicho arriendo habría terminado por la extinción del derecho del arrendador (art. $1950 \mathrm{~N}^{\mathrm{o}}$ 3), en Navarro con Lorca el Segundo Juzgado Civil de San Miguel rechazó la demanda de precario por lo siguiente:

"existiendo un vínculo contractual de arriendo respecto de la propiedad, a fin de evitar perjuicios para los contratantes, dar seguridad a las partes y asegurar que pueda la arrendataria hacer valer sus eventuales derechos en el procedimiento respectivo, debió la parte demandante accionar, precisamente y en juicio diverso, solicitando la declaración de extinción del derecho del arrendador, lo que no ocurre en la especie". ${ }^{27}$

En palabras de otro fallo, Boreal Inmobiliaria e Inversiones Ltda. con Godoy, "en el evento de que el propietario no esté obligado a respetar el arriendo en los términos establecidos en el artículo 1962 del Código Civil, podrá ejercer la acción contemplada en el artículo $7^{\circ}$ de la Ley 18.101 mediante el procedimiento previsto al efecto". ${ }^{28}$

Es decir, lo que el propietario tiene que hacer es demandar usando los juicios de arrendamiento porque la demandada tiene, a su vez, un derecho a hacer valer sus prerrogativas sobre el inmueble y son justamente estos procedimientos los que permiten discutir sobre la legitimidad de la ocupación así como sobre el cumplimiento de obligaciones y el eventual pago de indemnizaciones que estén pendientes.

Es por este motivo, precisamente, que se rechazan -por ejemplo- las

${ }^{27}$ Navarro con Lorca: Segundo Juzgado Civil de San Miguel, 17 de noviembre de 2014, Rol N ${ }^{\circ}$ 50544-2014, cons. $10^{\circ}$ (redacción del Juez Cristián García).

${ }^{28}$ Boreal Inmobiliaria e Inversiones Ltda. con Godoy: Vigésimo Juzgado Civil de Santiago, 24 de abril de 2013, Rol N 11712-2012, cons. 9 a 11º (redacción de la Jueza Gabriela Silva). 
demandas de precario que intenta el Consejo de Defensa del Estado, "sin perjuicio del derecho del dueño del inmueble a incoar la acción de restitución conforme a las normas en que se sustenta la demanda y relativas a los inmuebles fiscales", ${ }^{29}$ como es el caso de las viviendas que entrega Carabineros de Chile a sus funcionarios. Dichas normas se remiten a las atribuciones que tiene el Ministerio de Bienes Nacionales y, en último término, a las reglas de los juicios de arrendamiento. ${ }^{30}$

Por lo tanto, si bien el precario es un juicio rápido porque se tramita como un sumario, ${ }^{31}$ los diversos juicios de arrendamiento también son procedimientos rápidos $\mathrm{y}$, como ya se dijo, permiten solucionar temas que son propios de este contrato, como por ejemplo el derecho de retención que tiene el arrendatario desahuciado a quien aún se le adeude el pago de indemnizaciones (art. 597 (PC). ${ }^{32}$

${ }^{29}$ Fisco de Chile con Walker: Vigésimo Sexto Juzgado Civil de Santiago, 23 de enero de 2014, Rol N8806-2014, cons. $3^{\circ}$ (redacción del Juez Humberto Provoste).

${ }^{30} \mathrm{DL} \mathrm{N}^{\mathrm{o}} 1939$, normas sobre adquisición, administración y disposición de bienes del Estado, 10 de noviembre de 1977, art. 80: "El incumplimiento de cualesquiera de las obligaciones o la infracción a las prohibiciones establecidas en el presente párrafo, en sus reglamentos o en el decreto, resolución o contrato respectivo, será causal suficiente para poner término anticipado e inmediato al arrendamiento, en forma administrativa y sin responsabilidad alguna para el Fisco. (2) Corresponderá exclusivamente a la Dirección [de Tierras y Bienes Nacionales] determinar, en cada caso, la concurrencia de los hechos o circunstancias constitutivas del incumplimiento o infracción a que se refiere el inciso anterior. (3) La resolución respectiva será notificada al arrendatario en forma administrativa y le fijará un plazo prudencial, no inferior a treinta días, para la restitución del inmueble. (4) El afectado podrá reclamar ante la Dirección la ilegalidad de la referida resolución, dentro de los diez días siguientes a la notificación. Si el reclamo fuere rechazado por la Dirección, notificado el rechazo, el afectado, dentro de los diez días siguientes, podrá recurrir de apelación para ante la Corte de Apelaciones de la jurisdicción en cuyo territorio se encontrare ubicado el inmueble. Este recurso no suspenderá el cumplimiento de la resolución impugnada, a menos que la Corte estime que hay motivos plausibles y fundados para disponer que no se innove mientras se resuelve definitivamente el asunto. Este recurso se verá y resolverá en cuenta, con el sólo mérito de los antecedentes que ésta estime necesarios tener a la vista. (5) En estas gestiones el Fisco podrá actuar representado por abogados de la Dirección, sin perjuicio de las facultades que corresponden al Consejo de Defensa del Estado. (6) Si vencido el plazo a que se refiere el inciso $3^{\circ} \mathrm{o}$ los que resulten de la interposición de la apelación a que alude el inciso $4^{\circ}$, el arrendatario no hubiere desalojado el inmueble arrendado, la Dirección solicitará su lanzamiento de acuerdo a lo dispuesto en el artículo 595 del Código de Procedimiento Civill".

${ }^{31}$ Existe un debate en cuanto a cuál es la regla del Código de Procedimiento Civil en virtud de la cual el precario se tramita como un sumario, si el art. 680 inciso $2^{\circ} \mathrm{N}^{\circ} 6$ o el art. 680 inciso $1^{\circ}$, discusión que es importante para la tramitación del conflicto, ya que ella podría ser por completo sumaria, o bien, podría convertirse en una de lato conocimiento, LARROUCAU y ROSTIÓN, cit. (n. 1), pp. 86-88.

${ }^{32}$ Los escenarios que contempla el Código de Procedimiento Civil en el Título VI del Libro III son los siguientes: el desahucio (arts. 588 a 596), la restitución de la cosa arrendada por haber expirado el tiempo convenido (art. 604), el juicio de terminación inmediata del arrendamiento en las situaciones expresamente señaladas por la ley (arts. 607 a 610), el de terminación inmediata del arrendamiento por no pago de la renta (art. 611), el procedimiento para impedir el deterioro o mal uso del fundo 
Por lo demás, cuando corresponde aplicar el procedimiento de la Ley $\mathrm{N}^{\circ} 18.101$ las diferencias con el precario son aún más ostensibles: allí las partes pueden comparecer personalmente en primera instancia (art. $8 \mathrm{~N}^{\circ} 10$ ), el arrendador puede notificar a las empresas que suministran gas, energía eléctrica o agua potable con el propósito que el demandado sea el único responsable de los consumos mientras dure la ocupación del inmueble (art. 14); durante la audiencia la demandada puede reconvenir al actor (art. $8 \mathrm{~N}^{\circ} 4$ ); el llamado a conciliación puede tener lugar en cualquier momento (art. $8 \mathrm{~N}^{\circ}$ 5); y el tribunal, de oficio o a petición de parte, puede ordenar los medios de prueba que estime pertinentes (art. 15). ${ }^{33}$

De allí que sea cuestionable que, existiendo procedimientos específicos para la solución de conflictos relacionados con arriendos y teniendo ellos notorias diferencias respecto al precario, los dueños de inmuebles insistan en recuperarlos por esta vía. La jurisprudencia, por lo demás, ha sido bastante clara en cuanto a que esta pretensión no debería discutirse en un juicio de precario. El que esta inclinación se mantenga en la práctica es la que invita a discutir una serie de otros problemas, como, por ejemplo, la eficacia que podría tener en el precario la prueba que se rindió en un juicio previo de término de arrendamiento. Aparentemente la jurisprudencia no le reconoce ningún valor probatorio a este esfuerzo previo. Así, por ejemplo, hubo un caso en que la demandada ganó un juicio de arrendamiento seguido ante el Primer Juzgado de Letras de Talagante, confesando que no había arrendado el bien que usaba, pero esta confesión no fue tenida en cuenta en el juicio de precario que luego intentó el propietario, ahora ante el Segundo Juzgado de Letras de Talagante. ${ }^{34}$

En general, pareciera que en la jurisprudencia civil estos casos de prejudicialidad no son tomados en cuenta con la detención que merecen. Esto permite, por ejemplo, que alguien que ha perdido un juicio de arrendamiento (en donde afirmó la existencia de un título oponible a él como dueño) demande luego de precario (alegando la ausencia de cualquier título oponible), ${ }^{35} \mathrm{o}$ bien,

arrendado (art. 612), el de terminación del contrato de arriendo de servicios inmateriales (art. 613) y el destinado a hacer valer el derecho legal de retención a favor del arrendador o del arrendatario (arts. 597, 598 y 599). Ahora bien, el Mensaje del Proyecto de Código Procesal Civil del año 2012 advierte que en la reforma a la justicia civil estos casos serían regulados por una ley especial.

${ }_{33}$ Cornejo Aguilera, Pablo, El contrato de arrendamiento de bienes raices urbanos, Thomson Reuters, Santiago, 2012, pp. 237-278.

${ }^{34}$ Coz con Cruzat: Segundo Juzgado de Letras de Talagante, 26 de agosto de 2014, cit. (n. 11), cons. $9^{\circ}-12^{\circ}$.

${ }^{35}$ Jara con Fuentes: Juzgado Civil de Puente Alto, 14 de junio de 2013, Rol No 15627-2012, cons. $5^{\circ}$ (redacción de la Jueza Claudia Parga). 
que un demandado de precario que acompañó para defenderse una copia del fallo dictado en el juicio de arrendamiento -en donde se desestimó la acciónno pudiese luego impedir que se acogiera la demanda de precario, sin recibir ninguna explicación de parte del tribunal acerca del valor probatorio del primer fallo en conformidad con el art. 427 inciso $2 \mathrm{CPC},{ }^{36}$ salvo decir que dicho fallo no se encontraba firme. ${ }^{37}$

\section{La prueba del arrendamiento}

Entre las diferencias del precario con los juicios de arrendamiento, una de las que más destaca en la jurisprudencia actual es la facilidad que tiene el demandado de precario para demostrar el contrato, por diversas vías. La primera de ellas es la simple referencia al acuerdo.

En efecto, la sola alusión al arrendamiento que hace la propia actora en su demanda, por ejemplo, cuando reconoce que su ex cónyuge le arrendó el inmueble al demandado, ${ }^{38}$ ha permitido tener por probado el arriendo. En este sentido, se ha fallado que la mención del contrato que hace el dueño en su demanda le permite al juez presumir su existencia, ${ }^{39}$ ya que tiene "caracteres de gravedad y precisión suficientes". ${ }^{40}$

También se han aceptado las alusiones de terceros, por ejemplo, un escrito enviado por la administradora de la comunidad que demanda de precario, ${ }^{41} \mathrm{o}$ bien, lo dicho por ambas partes durante la audiencia en que se llama a conciliación, aunque no se logre un avenimiento. ${ }^{42}$

\footnotetext{
${ }^{36}$ Art. 427 CPC: "Sin perjuicio de las demás circunstancias que, en concepto del tribunal o por disposición de la ley, deban estimarse como base de una presunción, se reputarán verdaderos los hechos certificados en el proceso por un ministro de fe, a virtud de orden de tribunal competente, salvo prueba en contrario. (2) Igual presunción existirá a favor de los hechos declarados verdaderos en otro juicio entre las mismas partes".

${ }^{37}$ Inmobiliaria Larter S.A. con Pereira: Vigésimo Séptimo Juzgado Civil de Santiago, 29 de julio de 2014, Rol No 20291-2013, cons. $6^{\circ}$ y $7^{\circ}$ (redacción del Juez Javier Torres).

${ }_{38}$ Sánchez con Colombo: Décimo Octavo Juzgado Civil de Santiago, 9 de diciembre de 2013, Rol N ${ }^{\circ}$ 5145-2013, cons. $5^{\circ}$ (redacción de la Jueza Claudia Donoso).

${ }_{39}$ Muñoz con Araya: Vigésimo Sexto Juzgado Civil de Santiago, 5 de septiembre de 2014, Rol No 3934-2014, cons. $3^{\circ}$ (redacción del Juez Humberto Provoste).

${ }^{40}$ Meneses con Berrios: Primer Juzgado de Letras de Iquique, 26 de diciembre de 2014, Rol № 26402014, cons. $8^{\circ}$ (redacción del Juez Héctor Kompatzki).

${ }^{41}$ Comunidad Parque Residencial Agustinas con Guerra: Décimo Noveno Juzgado Civil de Santiago, 23 de septiembre de 2013, Rol N 4875-2013, cons. 13º (redacción de la Jueza Jacqueline Benquis).

42 Jaramillo con Heran: Vigésimo Sexto Juzgado Civil de Santiago, 22 de enero de 2015, Rol No 20882-2014, cons. $3^{\circ}$ (redacción del Juez Humberto Provoste).
} 
Por otro lado, en los típicos casos en que el inmueble fue arrendado al anterior dueño, la existencia del contrato se puede inferir, por ejemplo, del hecho que la actora sea socia de la dueña anterior ${ }^{43} \mathrm{o}$, nuevamente, porque así "se desprende del tenor" de su demanda de precario. ${ }^{44}$

Un segundo camino para probar el contrato dice relación con la prueba documental, por ejemplo, acompañar recibos de los pagos. ${ }^{45}$ Así ocurrió, por ejemplo, en una serie de demandas de precario que interpuso la Empresa de Ferrocarriles del Estado para tratar de recuperar unos inmuebles en Rancagua: se rechazaron las demandas en base a diversos comprobantes, por ejemplo, nueve recibos de pago entre 2004 y 2005, más una planilla de pago con el logo de la demandante (EFE) del año $2006,{ }^{46}$ tres liquidaciones de sueldo con un descuento por arriendo entre 1981 y $1982,{ }^{47} \mathrm{o}$ bien, con la autorización de descuento por planilla y más de treinta comprobantes de depósito. ${ }^{48}$ Con todo, también existen fallos que le han negado valor suficiente a estos recibos para probar el arriendo, señalando que ellos "solo prueban que se está en el inmueble, se reciben las boletas y se pagan, sin despejar si hay un arrendamiento o se está por mera tolerancia". ${ }^{49}$

En este último sentido, también se ha descartado la prueba documental señalando que "las constancias dejadas por la demandada ante Carabineros de Chile carecen de todo valor probatorio y no son un medio de prueba idóneo como para acreditar la existencia del contrato de arrendamiento que dicha parte señala que existe" ${ }^{50}$ Otro tanto se ha fallado tratándose "de fotocopias no certificadas o autorizadas por ministro de fe, algunas ilegibles [y que] ninguna

${ }^{43}$ Inversiones $M$ 'Cha Limitada con Céspedes: Vigésimo Octavo Juzgado Civil de Santiago, 21 de marzo de 2013, Rol No 11718-2012, cons. $9^{\circ}$ (redacción del Juez Jorge Mena).

${ }^{44}$ Mahmud con Sepúlveda: Vigésimo Noveno Juzgado Civil de Santiago, 10 de mayo de 2013, Rol $\mathrm{N}^{\circ} 28277-2012$, cons. $6^{\circ}$ (redacción del Juez Matías Franulic).

${ }^{45}$ Parra y Parra con Mena: Décimo Octavo Juzgado Civil de Santiago, 20 de noviembre de 2014, Rol N ${ }^{\circ} 11165-2014$, cons. $6^{\circ}$ (redacción de la Jueza Claudia Donoso).

${ }^{46}$ Empresa de Ferrocarriles del Estado con González: Segundo Juzgado Civil de Rancagua, 7 de octubre de 2013, Rol No 15507-2012, cons. $5^{\circ}$ (redacción de la Jueza Natalia Rencoret).

${ }^{47}$ Empresa de Ferrocarriles del Estado con Hormazábal: Segundo Juzgado Civil de Rancagua, 24 de enero de 2014, Rol No 431-2013, cons. $5^{\circ}$ (redacción de la Jueza Rosa Cáceres).

${ }^{48}$ Empresa de Ferrocarriles del Estado con Larenas: Segundo Juzgado Civil de Rancagua, 5 de marzo de 2014, Rol No 433-2013, cons. $5^{\circ}$ (redacción de la Jueza Natalia Rencoret).

${ }^{49}$ Inversiones e Inmobiliaria Dur Corp Limitada con Olguín: Vigésimo Segundo Juzgado Civil de Santiago, 28 de noviembre de 2014, Rol N 12964-2014, cons. $9^{\circ}$ (redacción del Juez Pedro García).

${ }^{50}$ Cisterna con Ávila: Vigésimo Primer Juzgado Civil de Santiago, 23 de abril de 2015, Rol No $21925-$ 2014, cons. $8^{\circ}$ (redacción del Juez Roberto Soto). 
relación tienen con la situación jurídica que se invoca por el demandado". ${ }^{51}$

Una tercera vía que se ha empleado para probar el arriendo en el precario es la prueba testimonial. En este caso, no es extraño que a las declaraciones de los testigos del demandado se les considere en sí mismas una prueba suficiente del contrato, incluso cuando no han dado mayores razones de sus dichos. Así, por ejemplo, en Maldonado con Cancino simplemente se declaró que "en el año 2001, la Sra. Hortensia se cambia a vivir a la comuna del Bosque y ella arrienda la casa a doña [...]", "ella pagó mes de arriendo y de garantía" y "el título por el que ocupa la propiedad es debido al arriendo". 52

Cabe notar que en el caso de la prueba testimonial los jueces muchas veces no aplican el estándar de admisibilidad de los arts. 1708 y 1709 del Código Civil cuando el contrato no consta por escrito. ${ }^{53}$ La razón de ello no podría ser el art. 2175 del Código Civil, que permite dicha prueba, que esta norma solo se aplica al comodato. ${ }^{54}$ En este sentido, se han citado como argumentos los arts. 1712 y 1713 del Código Civil, que exceptúan la prohibición de la prueba testimonial, pero sin indicar los motivos que justifican aplicar tal excepción en estos casos. ${ }^{55}$

Ahora bien, cuando no existe ninguna información acerca de si existe o no un arriendo, los tribunales tienen por no demostrado aplicando la carga de la prueba, considerando que es el demandado quien tiene la carga de probar la existencia de un título oponible al dueño. ${ }^{56}$

En cuanto al estándar de prueba exigido para demostrar el arriendo, los fallos consignan que se debe alcanzar el "nivel de convencimiento necesario para generar convicción" en quien juzga..$^{57}$

Por último, en caso de haber contradicción entre la información

\footnotetext{
${ }^{51}$ Sociedad Inmobiliaria Los Presidentes Limitada con Chuquimarca: Vigésimo Octavo Juzgado Civil de Santiago: 10 de noviembre de 2014, Rol No 5774-2014, cons. $7^{\circ}$ (redacción del Juez Jorge Mena).

${ }_{52}$ Maldonado con Cancino: Décimo Cuarto Juzgado Civil de Santiago, 8 de abril de 2014, Rol N ${ }^{\circ}$ 8275-2013, cons. $7^{\circ}$ y $8^{\circ}$ (redacción del Juez Osvaldo Correa).

${ }^{53}$ Art. 1708 CC: "No se admitirá prueba de testigos respecto de una obligación que haya debido consignarse por escrito"; Art. 1709 inciso $1^{\circ} \mathrm{CC}$ : "Deberán constar por escrito los actos o contratos que contienen la entrega o promesa de una cosa que valga más de dos unidades tributarias".

${ }^{54}$ Art. 2175 CC: "El contrato de comodato podrá probarse por testigos, cualquiera sea el valor de la cosa prestada".

${ }^{55}$ Briones con Campos: Primer Juzgado Civil de Puente Alto, 17 de septiembre de 2014, Rol № 34142014, cons. $5^{\circ}$ (redacción del Juez Jorge Gatica).

${ }^{56}$ Valdivia con Godoy: Primer Juzgado Civil de Puente Alto, 4 de noviembre de 2014, Rol No 12675 2013, cons. $6^{\mathrm{o}}$ y $7^{\mathrm{o}}$ (redacción del Juez Jorge Gatica).

${ }^{57}$ Olate con Alfaro: Primer Juzgado Civil de Puente Alto, 7 de noviembre de 2014, Rol No 11355-2013, cons. $4^{\circ}$ (redacción del Juez Jorge Gatica).
} 
disponible en el juicio (por ejemplo, en un caso en que la demandada confesó que no había arrendado el inmueble pero al mismo tiempo acompañó más de veinte depósitos de pago efectuados por su ex cónyuge), se ha resuelto que se tiene por no probado el arriendo. ${ }^{58}$ Esta decisión se debe tomar en base a la regla que señala que entre dos o más pruebas contradictorias el juez tiene que preferir la que crea más conforme a la verdad (art. 428 CPC).

\section{CONCLUSIÓN}

Este ensayo analizó una estrategia de litigación que existe en la práctica judicial chilena y que, a primera vista, no parece justificada: la preferencia del dueño de un inmueble arrendado de pedir su restitución mediante un juicio de precario y no por la vía de los juicios de arrendamiento.

En la primera parte se esbozaron algunas posibles explicaciones para esta elección del demandante. Una de ellas tiene que ver con las dudas en cuanto a si los arriendos celebrados con anteriores propietarios del bien son o no oponibles a quien demanda de precario. En la jurisprudencia reciente se tiende a considerar que dichos arriendos son títulos oponibles, de modo que el dueño no debería accionar por la vía del precario si pretende recuperar el inmueble.

La jurisprudencia, de hecho, sugiere algo más profundo: que el dueño no tiene derecho a optar por el precario, sino que debería acudir al procedimiento específico señalado por la ley para resolver el conflicto que lo aqueja, ya que estos juicios no solo cuentan con ventajas procesales para él -algunas que incluso son superiores a las del procedimiento sumario- sino que también han sido diseñados para vehicular de mejor manera las defensas que pueden presentar los demandados en un conflicto sobre el arriendo de un bien.

En la segunda parte, además, se consignaron las diferentes formas que ha ido reconociendo la jurisprudencia para tener por probado el arriendo en el juicio de precario. La facilidad que se observa para tener por probado este antecedente cuenta como una poderosa razón adicional para que el dueño se inhiba de ejercer la acción de precario y se incline, en su lugar, por el juicio de arrendamiento que corresponda.

${ }^{58}$ Durán con Contreras: Juzgado de Letras de Peñaflor, 25 de febrero de 2013, Rol No 2181-2011, cons. $8^{\circ}$ (redacción del Juez Felipe Prenafeta). 
BIBLIOGRAFÍA

Cornejo Aguilera, Pablo, El contrato de arrendamiento de bienes raíces urbanos, Thomson Reuters, Santiago, 2012, 294 pp.

ETCHEBERRY COURT, Leonor, “El título de precario: Análisis jurisprudencial cuando lo que se invoca como título es una relación de familia. ¿Se desprotege la propiedad?", en: Corral, H.; Manterola, P. (editores), Estudios de Derecho Civil XII, Thomson Reuters, Santiago, 2016, pp. 73-86.

Larroucau, Jorge; Rostión, Ignacio, "Del juicio de precario", en: Barcia Lehmann, R. (coord/editor), Fundamentos de derechos reales en el derecho chileno, LegalPublishing, Santiago, 2013, pp. 37-105.

Larroucau Torres, Jorge, 'La 'prueba completa' del dominio en la acción reivindicatoria", en: Turner, Susan; Varas, Juan A. (coords.), Estudios de Derecho Civil IX, Thomson Reuters, Santiago, 2014, pp. 103-123.

Ramos Pazos, René, "Del precario", Revista de Derecho Universidad de Concepción, 1986, № 186, pp. 7-19.

Rostión CASAS, Ignacio, El precario en la jurisprudencia chilena (1996 a 2013), LegalPublishing, Santiago, 2014, 203 pp.

JURISPRUDENCIA CITADA (EN ORDEN CRONOLÓGICO)

Lagazio con Divasto: Corte Suprema, 22 de mayo de 1995, Rol No 6749.

Sociedad Ferrando Rojas Limitada con Ceballos y otros: Corte de Apelaciones de Arica, 4 de julio de 2007, Rol N 184-2007.

Durán con Contreras: Juzgado de Letras de Peñaflor, 25 de febrero de 2013, Rol N 2181-2011.

Castillo con Oliva: Décimo Octavo Juzgado Civil de Santiago, 20 de marzo de 2013, Rol N² 20957-2012.

Inversiones $M$ `Cha Limitada con Céspedes: Vigésimo Octavo Juzgado Civil de Santiago, 21 de marzo de 2013, Rol No 11718-2012.

Boreal Inmobiliaria e Inversiones Ltda. con Godoy: Vigésimo Juzgado Civil de Santiago, 24 de abril de 2013, Rol No 11712-2012.

Silva con Marchant: Segundo Juzgado de Letras de San Bernardo, 30 de abril de 2013, Rol N 1535-2013.

Mahmud con Sepúlveda: Vigésimo Noveno Juzgado Civil de Santiago, 10 de mayo de 2013, Rol No 28277-2012.

Jara con Fuentes: Juzgado Civil de Puente Alto, 14 de junio de 2013, Rol No 15627-2012.

Tenis con Más Asesorías Deportivas Ltda. con Inmobiliaria e Inversio- 
nes Curacavi S.A.: Corte Suprema, 9 de julio de 2013, Rol No 8304-2012.

Contreras con Santibáñez: Vigésimo Juzgado Civil de Santiago, 19 de agosto de 2013, Rol N 5332-2013.

Comunidad Parque Residencial Agustinas con Guerra: Décimo Noveno Juzgado Civil de Santiago, 23 de septiembre de 2013, Rol No 4875-2013.

Empresa de Ferrocarriles del Estado con González: Segundo Juzgado Civil de Rancagua, 7 de octubre de 2013, Rol No 15507-2012.

Sánchez con Colombo: Décimo Octavo Juzgado Civil de Santiago, 9 de diciembre de 2013, Rol No 5145-2013.

Fisco de Chile con Castro: Tercer Juzgado Civil de San Miguel, 19 de diciembre de 2013, Rol No 14077-2011.

Fisco de Chile con Walker: Vigésimo Sexto Juzgado Civil de Santiago, 23 de enero de 2014, Rol No 8806-2014.

Empresa de Ferrocarriles del Estado con Hormazábal: Segundo Juzgado Civil de Rancagua, 24 de enero de 2014, Rol No 431-2013.

Empresa de Ferrocarriles del Estado con Larenas: Segundo Juzgado Civil de Rancagua, 5 de marzo de 2014, Rol No 433-2013.

Maldonado con Cancino: Décimo Cuarto Juzgado Civil de Santiago, 8 de abril de 2014, Rol No 8275-2013.

Inmobiliaria Larter S.A. con Pereira: Vigésimo Séptimo Juzgado Civil de Santiago, 29 de julio de 2014, Rol No 20291-2013.

Sarras con López: Vigésimo Sexto Juzgado Civil de Santiago, 20 de agosto de 2014, Rol No 4849-2014.

Coz con Cruzat: Segundo Juzgado de Letras de Talagante, 26 de agosto de 2014, Rol N²64-2013.

Inmobiliaria e Inversiones Socorro Limitada con Valdebenito: Cuarto Juzgado de Letras de Talca, 28 de agosto de 2014, Rol N 517-2014.

Muñoz con Araya: Vigésimo Sexto Juzgado Civil de Santiago, 5 de septiembre de 2014, Rol N³934-2014.

Briones con Campos: Primer Juzgado Civil de Puente Alto, 17 de septiembre de 2014, Rol N 3414-2014.

BBVA Chile con Velásquez: Segundo Juzgado de Letras de Quilpué, 4 de noviembre de 2014, Rol No 1152-2014.

Valdivia con Godoy: Primer Juzgado Civil de Puente Alto, 4 de noviembre de 2014, Rol No 12675-2013.

Olate con Alfaro: Primer Juzgado Civil de Puente Alto, 7 de noviembre de 2014, Rol No 11355-2013.

Sociedad Inmobiliaria Los Presidentes Limitada con Chuquimarca: Vigésimo Octavo Juzgado Civil de Santiago: 10 de noviembre de 2014, Rol No 
5774-2014.

Navarro con Lorca: Segundo Juzgado Civil de San Miguel, 17 de noviembre de 2014, Rol № 50544-2014.

Parra y Parra con Mena: Décimo Octavo Juzgado Civil de Santiago, 20 de noviembre de 2014, Rol No 11165-2014.

Inmobiliaria Andrea Jara Hermosilla con Jaccard: Segundo Juzgado de Letras de Concepción, 21 de noviembre de 2014, Rol N 7018-2014.

Inversiones e Inmobiliaria Dur Corp Limitada con Olguín: Vigésimo Segundo Juzgado Civil de Santiago, 28 de noviembre de 2014, Rol No $12964-$ 2014.

Meneses con Berrios: Primer Juzgado de Letras de Iquique, 26 de diciembre de 2014, Rol N² 2640-2014.

Jaramillo con Heran: Vigésimo Sexto Juzgado Civil de Santiago, 22 de enero de 2015, Rol No 20882-2014.

Veas con Vergara y Vergara: Primer Juzgado de Letras de San Felipe, 27 de enero de 2015, Rol No 4039-2014.

Monsalve con Roa: Segundo Juzgado Civil de Talcahuano, 4 de febrero de 2015, Rol N³267-2014.

Salvo con Galdames: Vigésimo Segundo Juzgado Civil de Santiago, 6 de febrero de 2015, Rol No 18948-2014.

Monroy con Andana y Martínez: Primer Juzgado de Letras de San Carlos, 27 de febrero de 2015, Rol No 372-2014.

Toloza con Carrasco: Juzgado de Letras de Buin, 13 de abril de 2015, Rol No 1613-2013.

Cisterna con Ávila: Vigésimo Primer Juzgado Civil de Santiago, 23 de abril de 2015, Rol No 21925-2014. 